\title{
Commentary
}

\section{Congenital anterior urethrocutaneous fistula}

\section{T}

he report of the two cases of congenital urethrocutaneous fistula is yet another addition to the the list of rare anomalies of male external genitalia. Anterior congenital urethral fistula is the rarest among a spectrum of congenital urethrocutaneous fistula that run from penile to the scrotal area. Not more than 20 cases of anterior congenital penile urethral fistula have been reported in english literature so far. ${ }^{[1]} \mathrm{A}$ brief overview of the embryogenesis of the male external genitalia is necessary to understand the genesis of this anomaly [Figure 1]. While the genital tubercle is getting elongated to form the phallus, the urethral fold gets pulled and forms the lateral walls of the urethral groove. This groove extends along the caudal aspect of the phallus till the corona. By end of $3^{\text {rd }}$ month of intrauterine life as a result mesenchymal proliferation underneath the urethral folds, they coalesce over the urethral plate to form the penile urethra. One month later, the ectodermal cells of the tip of the glans penetrate inwards to form a chord. This cord later obtains a lumen forming the external meatus and glanular urethra which joins proximally with the penile urethra which is already formed. ${ }^{[2]}$ The authors have mentioned the different embryological theories explaining the aetiology of this anomaly. The most plausible cause of this congenital anomaly is a focal dehiscence of the coalescing urethral folds or a segmental deficiency of the urethral folds. ${ }^{[3]}$ This results in a spectrum of defect ranging from pinpoint fistula to a large ovoid ventral defect. The coronal version is the result of failure to align the proximally directed canalization of the glanular urethra with already formed penile urethra. ${ }^{[3]}$ The theory of focal defect of urethral plate also gives credence to the fact that urethra distal to the fistula is normal and encased in healthy spongiosum. This is in contrast to hypospadias where

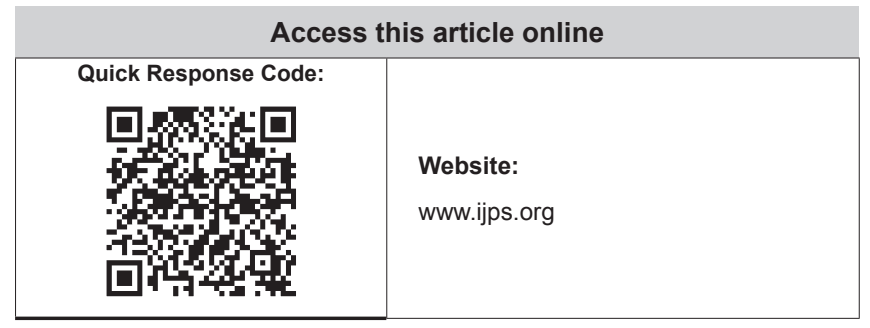

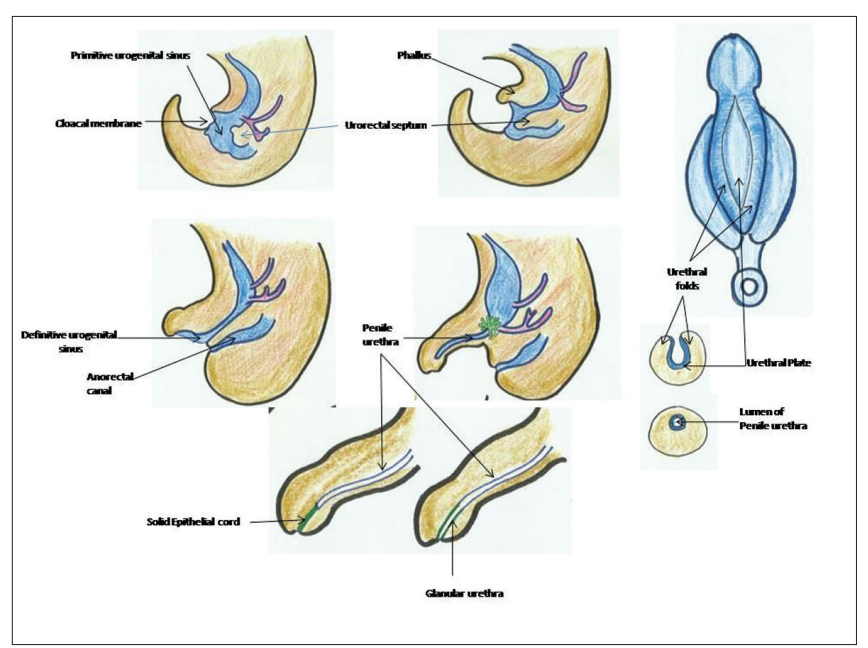

Figure 1: Embryogenesis of male external genitalia

there is arrest of the proximal to distal coalescing of the urethral folds forming the urethral tube. In these cases, there is concurrent deficiency of inner genital fold which gives rise to the analge of corpus spongiosum. A variant of congenital anterior fistula is known to be associated with hypospadias and chordee. ${ }^{[4]}$ But these cases are basically hypospadias where there is a flimsy skin tunnel masquerading urethra proximal to the ectopic meatus. This flimsy skin tunnel often breaks down to form a fistula. In such cases, there is associated chordee and the spongiosum is absent distally as well as under the flimsy skin tunnel. The congenital posterior urethral fistula is a result of the defect of urogenital membrane, cloacal membrane, and primitive urogenital sinus. ${ }^{[4]}$ The primitive urogenital sinus gets divided into definitive urogenital sinus and the anorectal canal. The prostatic and the membranous urethra develop from definitive urogenital sinus [Figure 1]. ${ }^{[2]}$ This explains the associations of congenital posterior urethral fistula with imperforate anus and the fistula sometimes represent a $Y$ type urethral duplication. ${ }^{[4]}$ The posterior variant is more common than the anterior type.

The principle of hypospadias repairs apply to the repair of congenital anterior urethral fistula as well. But it is important to tailor the surgical technique according to the site and size of the fistula. Before planning a repair, 
it is important to rule out $\mathrm{Y}$ type urethral duplication and check the patency and calibre of the distal urethra. It is also important to note the quality of spongiosum distal to the fistula. Meatal stenosis must be corrected before repairing the fistula. Cases where there is hypospdias along with a fistula overlying a skin tunnel it is imperative to do a formal hypospadias repair. The skin tunnel is opened up till the real meatus and healthy spongiosum is reached. The chordee is released and formal urethroplasty is done either in same stage or in second stage.

Treatment of isolated congenital anterior fistulas depends upon its size. Small fistulas ranging from pin-point to less than $0.5 \mathrm{~mm}$ as described by the authors can easily be primarily closed by freshening the edges and the skin is closed over it. Larger fistulas ranging from 0.5 to $1 \mathrm{~cm}$ can be closed with the help of turnover flaps based on the edge of the fistula. ${ }^{[4]}$ Defects more than $1 \mathrm{~cm}$ can be closed by tubularized incised plate urethroplasty by giving urethral plate relaxing incision through the fistula or by Thiersch Duplay technique. ${ }^{[3,5]}$ Dennis Brown principle has also been used in such defects where the urethral plate is buried under the skin flaps mobilized from the two sides of the fistula. ${ }^{[5]}$ Fistulas more than $2 \mathrm{~cm}$ in width have significant tissue deficit both in urethra and skin cover. Such defects urethra can easily be addressed by bilamelar prepucial island flap where the inner prepucial skin reconstructs the urethra and the outer skin provides cover. ${ }^{[6]}$ In these cases urethra can also be reconstructed by buccal mucosal grafts. ${ }^{[7]}$ Recurrence of fistula after repair poses a major challenge both for congenital and post hypospadias repair fistulas. The overall recurrence rate in all types of fistula reported in the literature is about $10-30 \% .{ }^{[5-7]}$ This has inspired surgeons to device modalities of waterproofing. De-epithilialised turn over flaps interposed between urethral repair and the skin cover has been reported as techniques of water proofing. ${ }^{[8]}$ In our experience, the dermal graft interposition also prevents recurrence of fistula. Avoiding the overlap of skin suture urethral suture line also reduces the chances of recurrence of the fistula. To achieve this rotation flap from the adjoining penile skin can be done so that flap suture line is away from the urethral repair. ${ }^{[4]}$ Same purpose can be served by transposing the whole degloved penile skin ventrally to cover the urethral repair and having the skin suture line dorsally. ${ }^{[1]}$

This congenital defect is relatively rare and knowledge about this clinical entity along with high level of suspicion helps in the diagnosis.

\section{Sameek Bhattacharya}

Department of Burns, Plastic and Maxillofacial Surgery, PGIMER and Dr. RML Hospital, New Delhi, India

Address for correspondence: Dr. Sameek Bhattacharya, Department of Burns, Plastic and Maxillofacial Surgery, PGIMER and Dr. RML Hospital, New Delhi, India. E-mail: sameekb@gmail.com

\section{REFERENCES}

1. Bhattacharya S. A modified tubularised incised plate urethroplasty technique and a revised hypospadias algorithm. Indian J Plast Surg 2010;43:21-7.

2. Lamahewage A. Urogenital system. In: Langman's Medical Embryology. William and Wilkins Baltimore; 1995. p. 272-311.

3. Rashid KA, Kureel SN, Tandon RK. Congenital anterior isolated urthrocutaneous fistula: A case report. Afr J Paediatr Surg 2008;5:52-3.

4. Agarwal P. Congenital anterior urethrocutaneous fistula revisited. Ind J Plast Surg 2004;37:64-5.

5. Gupta V, Sharma SB. A new indication for tabularized incised plate urethroplasty: Isolated congenital penile urtherocutaneous fistula. Indian J Pediat Surg 2006;11:148-50.

6. Islam MK. Congenital penile urethrocutaneous fistula. Indian J Pediatr 2001;68:785-6.

7. Betalli P, Carretto E, Midrio P, Zanon GF, Gamba PG. A new indication for buccal mucosal graft: Isolated congenital fistula of the penile urethra. Pediatr Surg Int 2003;19:586-7.

8. Ahuja RB. A de-epithelialised'turnover dartos flap' in the repair of urethral fistula. J Plast Reconstr Aesthet Surg 2009;62:374-9.

How to cite this article: Bhattacharya S. Congenital anterior urethrocutaneous fistula. Indian J Plast Surg 2012;45:566-7.

Source of Support: Nil, Conflict of Interest: None declared. 